\title{
DETERMINATION OF FREE EXCITON CAPTURE CROSS SECTION OF Si:AI BY PHOTOLUMINESCENCE
}

\author{
G. Schramm \\ VEB Spurenmetalle Freiberg-WIB im VEB Kombinat Mikroelektronik Erfurt \\ PSF 211, 9200 Freiberg, Germany
}

(Received April 9, 1990)

\begin{abstract}
The free excitons capture rate and capture cross-section of the neutral $\mathrm{Al}$ atom in silicon were determined at $4.2 \mathrm{~K}$. The obtained values are of the same order of magnitude as reported values of other shallow dopants.
\end{abstract}

PACS numbers: $78.55 .-\mathrm{m}$

Free exciton (FE) capture cross-section $\left(\sigma_{0}\right)$ in silicon was determined for In $[1,2], \mathrm{B}[2,3], \mathrm{P}[3,4], \mathrm{Li}[5]$ and $\mathrm{Sb}[6]$. The $\sigma_{0}$ value for $\mathrm{Si}: \mathrm{Al}$ seems to be absent in the literature. The aim of this note is to calculate this quantity at $4.2 \mathrm{~K}$.

The FE capture rate $\left(c_{0}\right)$ of $\mathrm{Al}$ is evaluated from the changes of the relative intensities of photoluminescence (PL) spectra as a function of excitation density according to [4]. Two samples with different concentrations of $\mathrm{Al}\left(N_{\mathrm{Al}}\right)$ were measured. In Fig. 1 the PL spectrum of the higher doped sample is shown. The analysis, with the help of calibration curves, yields $N_{\mathrm{Al}}=5.3 \times 10^{14} \mathrm{~cm}^{-3}$ and $N_{\mathrm{Al}}=1.4 \times 10^{13} \mathrm{~cm}^{-3}$ for the two samples. The capture rate $c_{0}$ is calculated according to

$$
c_{0}=\sigma_{0} v_{\mathrm{th}}=\frac{R_{\mathrm{b} / \mathrm{f}}^{0}\left(q, q^{\prime}\right)}{W_{\mathrm{b} / \mathrm{f}}\left(q, q^{\prime}\right) N_{\mathrm{Al}} \tau_{\mathrm{Al}}^{\mathrm{BE}}},
$$

where $v_{\mathrm{th}}$ is the average thermal velocity of $\mathrm{FE}, R_{\mathrm{b} / \mathrm{f}}^{0}\left(q, q^{\prime}\right)$ is the ratio of the peak heights of bound exciton (BE) and FE-related luminescence for diminishing excitation density, $q$ and $q^{\prime}$ are the participating phonons in recombination and $W_{\mathrm{b} / \mathrm{f}}\left(q, q^{\prime}\right)$ denotes the ratio of radiative transition rates of $\mathrm{BE}$ relative to FE. The nonradiative Auger transition rate of an exciton bound to $\mathrm{Al}\left(\tau_{\mathrm{Al}}^{\mathrm{BE}}=\right.$ $76 \mathrm{~ns})$ was taken from [7]. To calculate $W_{\mathrm{b} / \mathrm{f}}(\mathrm{NP}, \mathrm{TO})$ one needs the intrinsic full width at half maximum (FWHM) of the corresponding peaks. These values are sample-dependent and have to be evaluated. FWHM of the $\mathrm{Al}_{\mathrm{NP}}(\mathrm{J}=0)$ peak 


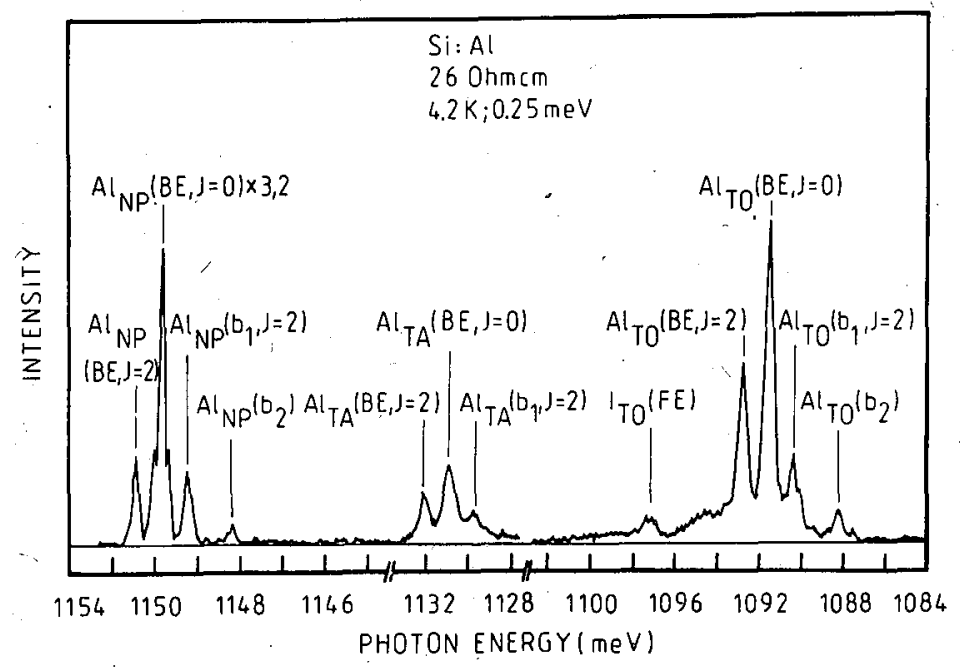

Fig. 1. PL spectrum (uncorrected for system response) of a Al-doped sample (resistivity $\varrho=26 \mathrm{Ohm} \mathrm{cm}, N_{\mathrm{Al}}=5.3 \times 10^{14} \mathrm{~cm}^{-3}$ ).

$0.10 \mathrm{meV}$ and FWHM of the intrinsic peak $I_{\mathrm{TO}}(\mathrm{FE}) 0.63 \mathrm{meV}$ were determined for the higher doped sample. $W_{\mathrm{b} / \mathrm{f}}(\mathrm{NP}, \mathrm{TO})$ was calculated using these values, the oscillator strenght given by Dean et al. [8] and the relative NP oscillator strengths [9]. The computation gives

$$
W_{\mathrm{b} / \mathrm{f}}(\mathrm{NP}, \mathrm{TO})=2.3 \pm 0.7 .
$$

The excitation power dependence of the peak heights of BE- and FE-related luminescence is depicted in Fig. 2. Figure 3 shows the reciprocal peak height ratios $R_{\mathrm{b} / \mathrm{f}}^{-1}(\mathrm{NP}, \mathrm{TO})$ and $R_{\mathrm{b} / \mathrm{f}}^{-1}(\mathrm{TO}, \mathrm{TO})$ of the higher doped sample as functions of the excitation power $P$. From the intersection of $R_{\mathrm{b} / \mathrm{f}}^{-1}(\mathrm{NP}, \mathrm{TO})$ with the vertical axis (diminishing excitation power) one obtains $R_{\mathrm{b} / \mathrm{f}}(\mathrm{NP}, \mathrm{TO})$. The capture rate $c_{0}$ was evaluated with the above mentioned $\tau_{\mathrm{Al}}^{\mathrm{BE}}, W_{\mathrm{b} / \mathrm{f}}(\mathrm{NP}, \mathrm{TO})$ and $R_{\mathrm{b} / \mathfrak{f}}^{0}(\mathrm{NP}, \mathrm{TO})$ corrected for "spectrometer broadening". This gives

$$
\begin{gathered}
c_{0}=(5.5 \pm 1.9) \times 10^{-7} \mathrm{~cm}^{3} s^{-1} \text { and } \\
\sigma_{0}=(3.4 \pm 1.2) \times 10^{-13} \mathrm{~cm}^{2} \quad \text {, respectively. }
\end{gathered}
$$

This to our knowledge is the first estimation of the FE capture cross-section of $\mathrm{Al}$ in $\mathrm{Si}$ measured at $4.2 \mathrm{~K}$. This cross-section is of the same order of magnitude as the reported values of other shallow dopants in $\mathrm{Si}[1-6]$. The same values were obtained using the lower doped sample or the TO region of the $\mathrm{BE}$ recombination. 


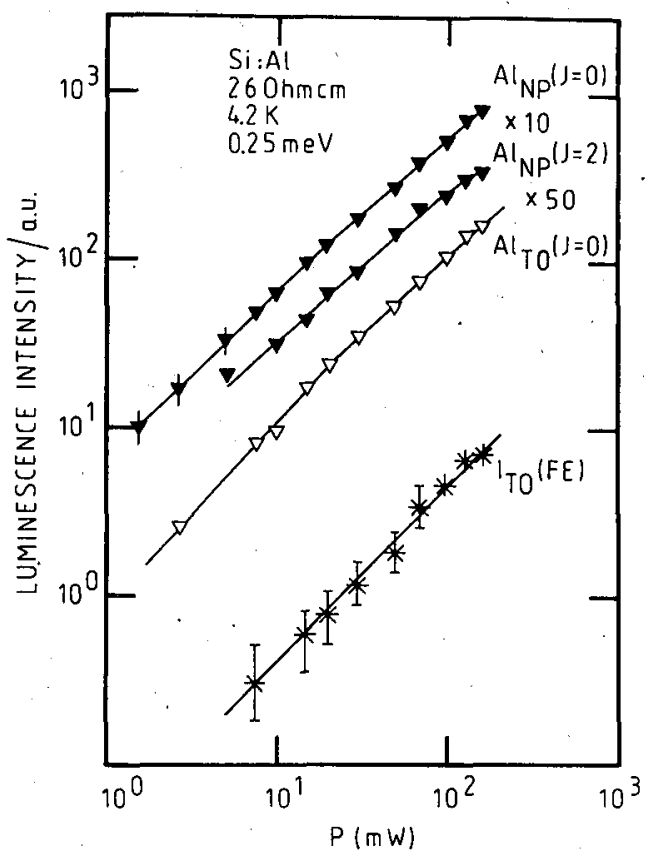

Fig. 2. Excitation power dependence of peak heights of BE- and FE-related luminescence.

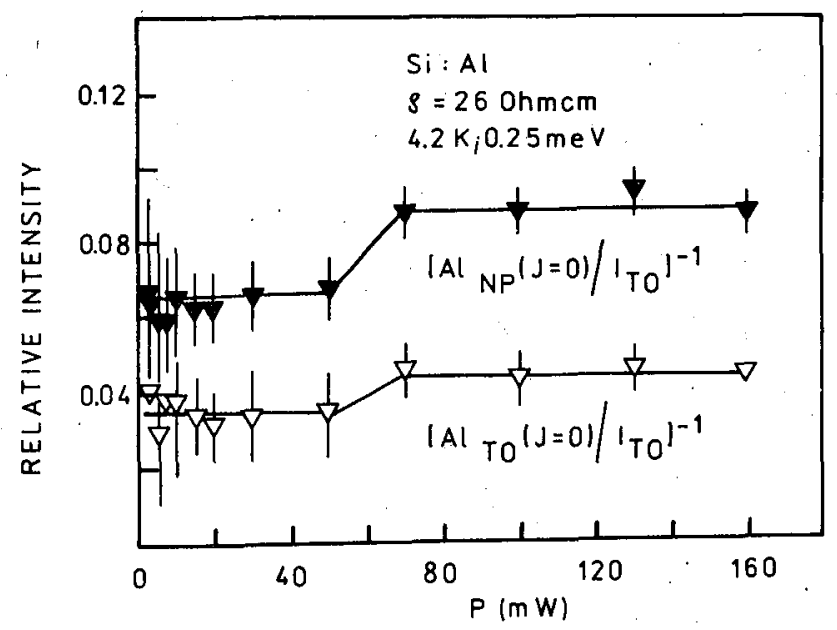

Fig. 3. Reciprocal peak height ratios $R_{\mathrm{b} / \mathrm{i}}^{-1}(\mathrm{q}, \mathrm{TO})$ as functions of the excitation power $P$. 


\section{References}

[1] K.R. Elliott, D.L. Smith, T.C. McGill, Solid State Commun. 24, 461 (1977).

[2] R.M. Feenstra, T.C. McGill, Solid State Commun. 36, 1039 (1980).

[3] R.B. Hammond, R.N. Silver, Appl. Phys. Lett. 36, 68 (1980).

[4] H. Nakayama, T. Nishino, Y. Hamakawa, Jpn. J. Appl. Phys. 19, 501 (1980).

[5] K. Ohnishi, H. Nakayama, T. Nishino, Y. Hamakawa, J. Phys. Soc. Jpn. 49, 1078 (1980).

[6] G. Schramm, Phys. Status Solidi A 116, K209 (1989).

[7] W. Schmid, Phys. Status Solidi B 84, 529 (1977).

[8] P.J. Dean, W.F. Flood, G. Kaminsky, Phys. Rev. 163, 721 (1967).

[9] K.R. Elliott, G.C. Osbourn, D.L. Smith, T.C. McGill, Phys. Rev. B 17, 1808 (1978). 